\title{
Decomposition of the modeling task of some objects of archeological research for processing in a distributed computer system
}

\author{
O. O. Iakushkina, A. B. Degtyarev, S. V. Shvemberger \\ Saint Petersburg State University, University ave. 35, Peterhof, St. Petersburg, 198504, Russia \\ E-mail: a Oleg.jakushkin@gmail.com
}

Received October 10, 2014

\begin{abstract}
Although each task of recreating artifacts is truly unique, the modeling process for façades, foundations and building elements can be parametrized. This paper is focused on a complex of the existing programming libraries and solutions that need to be united into a single computer system to solve such a task. An algorithm of generating 3D filling of objects under reconstruction is presented. The solution architecture necessary for the system's adaptation for a cloud environment is studied.
\end{abstract}

Keywords: distributed systems, cloud computing, modeling, reconstructions, service application architecture

\section{Декомпозиция задачи моделирования некоторых объектов археологи- ческих исследований для работы в распределенной вычислительной среде}

\section{О. О. Якушкин, А. Б. Дегтярев, С. В. Швембергер}

Санкт-Петербургский государственный университет, Россия, 198504, г. Санкт-Петербург, Петергоф, Университетский просп., д. 35

В то время как каждая задача воссоздания артефактов уникальна, моделирование фасадов, фундаментов и конструктивных элементов строений может быть параметризовано. В работе рассмотрен комплекс существующих программных библиотек и решений, которые необходимо объединить в единую вычислительную систему для решения такой задачи. Представлен алгоритм генерации трехмерного заполнения реконструируемых объектов. Рассмотрена архитектура решения, необходимая для переноса системы в облачную среду.

Ключевые слова: сетевые распределенные вычисления, облачные вычисления, моделирование, реконструкция, сервисная архитектура

The work has been done with partial support of SPbU grant 9.38.674.2013, SPbU grant 9.37.157.2014 and RFBR grant No. 13-07-747. The research has been done using the computing resources of the resource center "SPbU Computing Facility" (http://cc.spbu.ru).

Citation: Computer Research and Modeling, 2015, vol. 7, no. 3, pp. 533-537. 


\section{Introduction}

Visualization of architectural monuments' reconstruction and modeling of historical events of the past have always been an overarching challenge of historical studies. Our study is devoted to highlighting a pile of tasks aimed at reconstruction of certain classes of architectural objects requiring computer-aided modeling as an optimal solution in terms of authenticity and effort.

Although each task of recreating artifacts is truly unique, the modeling process for façades, foundations and building elements can be parametrized. Practically it means that the details of each single stone/block/slab constituting the reconstructed object may at the first stage be elaborated in a distributed computer environment without an artist's aid.

We have studied a complex of the existing programming libraries and solutions that need to be united into a single computer system to solve such a task. Its essential character is defined by a current practice, when, for the sake of the authenticity of the image and structures' collapse, artists have to model whole buildings using a single stone, that being incomparable to a computer-aided solution in terms of effort.

\section{Task decomposition}

\section{The algorithm of object recreation}

At present, various solutions are used for 3D object modeling. These are polygonal modeling packages; solutions with an option of giving volume and additional properties to objects during rendering; architectural modeling programs. At SPbU, the most frequently used modeling packages for interactive installations are Maya 2014 and 3ds Max 2014. They have no option of filling the given volume with similar objects with unique characteristics "out of the box". In other words, the software that artists use for modeling has no tools that make it possible to create stone blocks directly. Moreover, they require substantial computing resources for processing of large arrays of created objects which is crucial when the recreated model should be destroyable by means of animation. As a result, an approach has been developed, enabling the creation of single stones and whole walls as individual objects by introduction of possible random disturbances.

An algorithm of creating structures made of unique stones that can be composed (and decomposed) in a 3D space has been developed. The algorithm is based on the work with point clouds and their clusterization. This algorithm is based on working with parallelepiped-shaped bound enclosed volumes. Local grids acting as an analogue of the surface of a torus with a dimension greater by one than that of the studied volume are defined in parallelepiped-shaped bound enclosed volumes. For instance, if we have a ball with one (parallelepiped-shaped bound enclosed volumes)-type volume in diameter in the form of a cube with the side one, we shall see, upon moving the ball's center to the zero point, that the ball is split into eighths, each of them being located in the cube's angles see fig. 1 for $2 \mathrm{D}$ example.

Let us assume that there is a primitive, a point cloud, which is a mapping of a real world object into the world of points (i.e. that of a sphere).

Given an enclosed space of the parallelepiped-shaped bound enclosed volumes $\mathrm{C}$ type partitioned into $\mathrm{n}$ equal subspaces of the parallelepiped-shaped bound enclosed volumes type, each of them also partitionable. The number of inclusions must be limited. Each subspace in partitioning must have its own unique index.

Let us assume that the primitive has been inscribed into the smallest subspace, so that its position and size functionally depend on the index of the subspace it is being inscribed into. Let us suppose that similar dependence exists between the inscribed subspace and the space it is inscribed into.

Here the inclusion of the subspaces into the $\mathrm{C}$ space as well as their aspect ratio will define such masonry parameters as width, height, length and the number of layers.

By choosing the initial primitive and its distribution functions, as well as by noise masking and distortion operations performed above the points of the $\mathrm{C}$ space, it is possible to obtain the desired characteristics of the material's surface appearance.

Then the masonry array is decomposed into particular fragments by means of clusterization. 


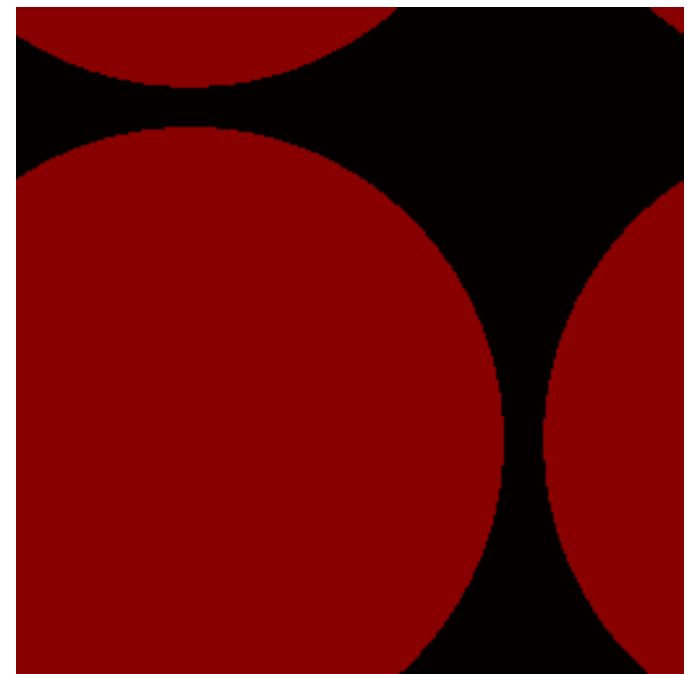

Fig 1: A circle in a $2 \mathrm{~d}$ box parallelepiped-shaped bound enclosed volumes

\section{The algorithm implementation}

Today, there are several main libraries studied for the sake of the implementation of this algorithm. These are Point Cloud Library (PCL) and OpenVDB. Despite the fact that PCL has broad image capturing options to work with point clouds as well as data segmentation and filtration options, we have developed a small OpenVDB-based prototype. This library was chosen due to its convenience when working with nested hierarchical data structures.

The polygonal grid optimality is an important aspect of creating geometry. To optimize the grid developed as a result of using the algorithm, the OpenSubdiv library was used. This library makes it possible to decrease the number of polygons in the end model with no loss in quality. The algorithm's operability has been tested within the framework of the prototype.

\section{Solution adaptation for cloud architecture}

We have performed further task decomposition into the necessary components and means in order to prepare the project for implementation to solve field-specific tasks.

Modeling of a large number of objects made of such structures, i.e. the streets of an ancient town, requires high computational power. It is noteworthy that many libraries working with $3 \mathrm{D}$ graphics support GPU coprocessors "out of the box", OpenSubdiv being one of them.

Strict requirements to the modeling speed as well as the volume of needed calculations require the development of a service system existing in a distributed computer system. As a result, the solution is divided into a client application working in the modeling software used by the artist and a server application performing analyses and calculations automatically.

Porting out the main mechanism of model development to the service layer makes it possible to make the client thinner and the system in general, in the long view, applicable to deployment into various means of visual modeling.

To take into account any changes in the service system, the extension installed into the programming package should be updatable. This paper provides a description of how such an update should take place (Fig. 2).

The given service architecture makes it possible to extend the functionality at the data preprocessing and post-processing levels beyond the 3D modeling system. Thus, we can, at the preprocessing stage, request visual information about the object the user is working with and offer modeling service settings for such an object. At the post-processing stage, we can offer the user to choose the point cloud region he/she wants to visualize. The given architecture provides for soft updates of 
the system. In other words, it enables creation, testing and deployment of new components of the system without interrupting the users' current sessions for updates.

\section{Frontend}

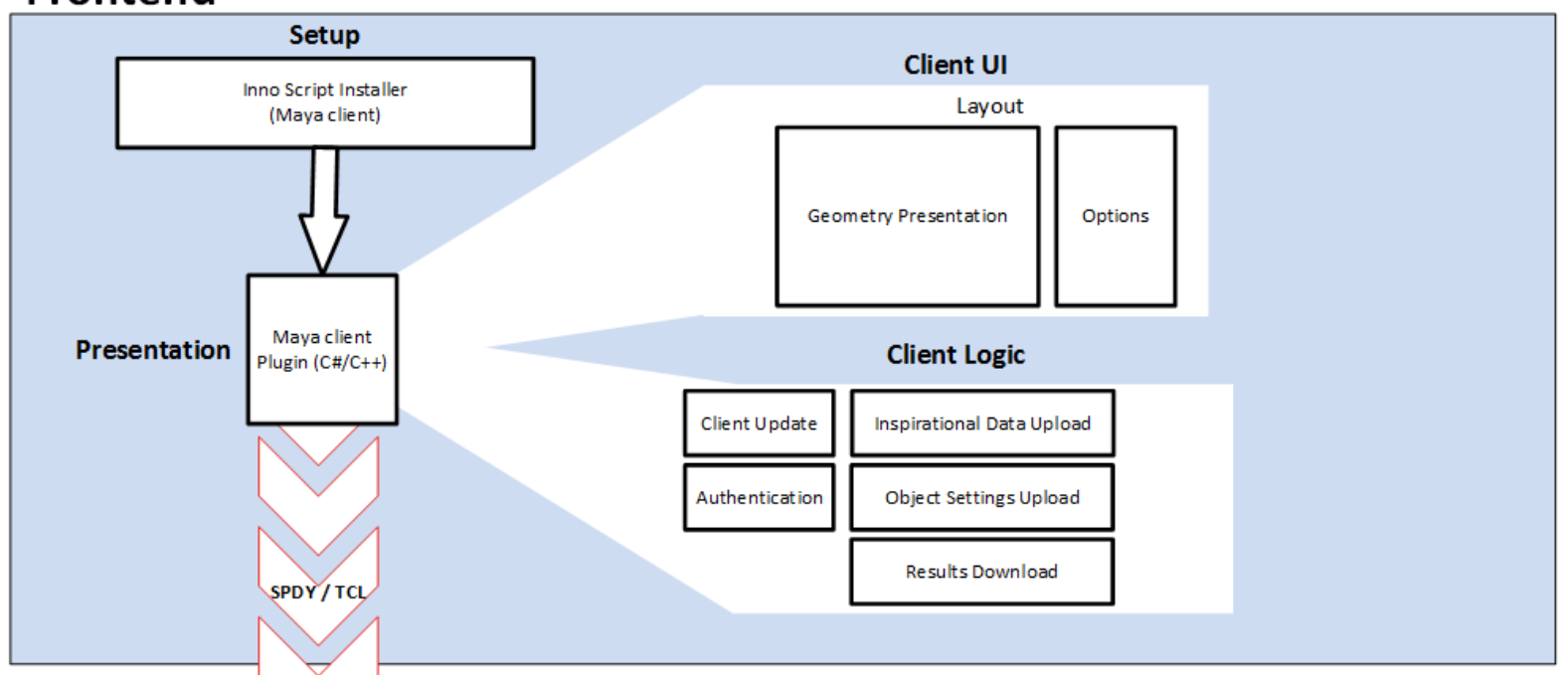

\section{Backend}

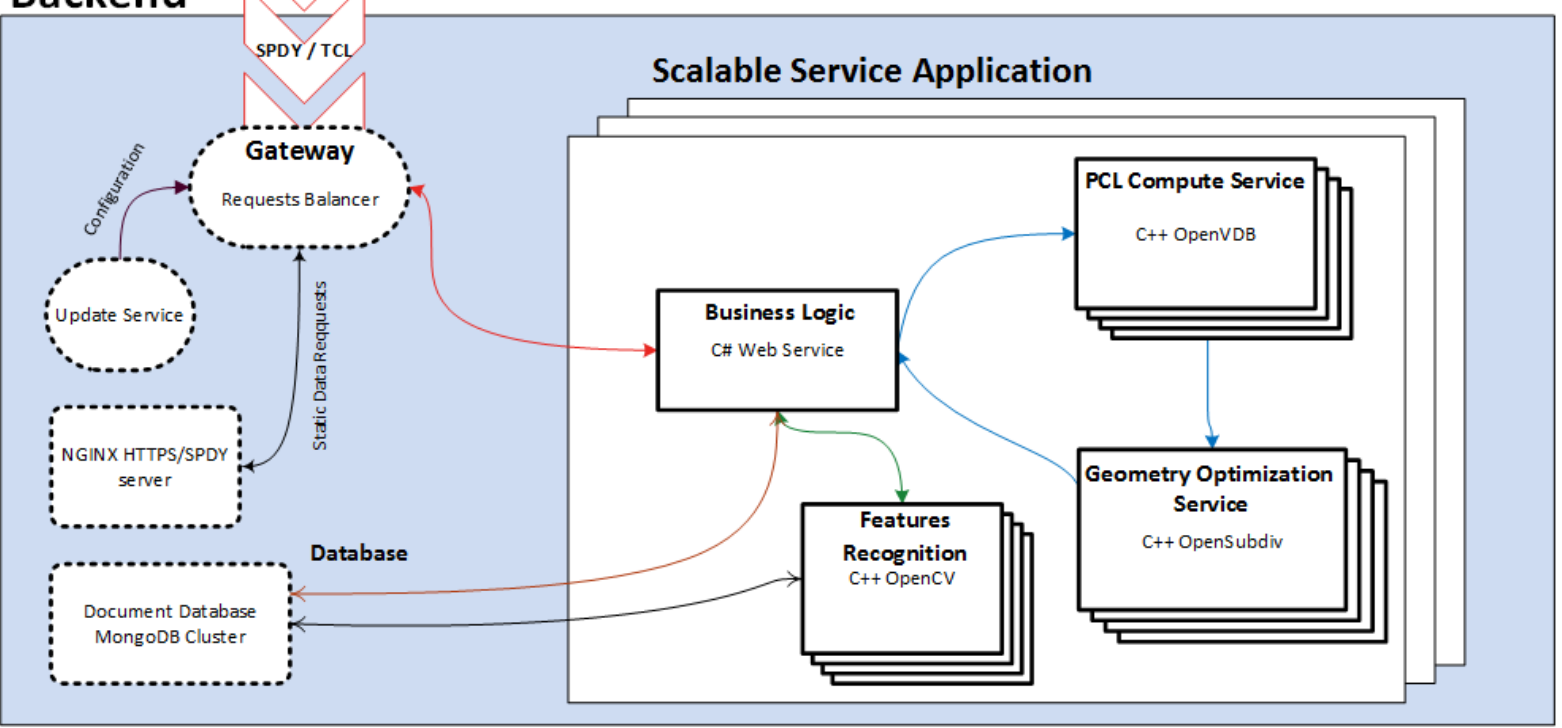

Fig. 2: The architecture of the offered service solution

\section{Conclusion}

Solutions of the modeling task of particular objects of archeological research have been elaborated. The architecture enabling the given system's work in a distributed computer system using service architecture has been described. Its scaling and further development points have also been described.

\section{References}

Museth, K., Lait, J., Johanson, J., Budsberg, J., Henderson, R., Alden, M., \& Pearce, A. OpenVDB: an open-source data structure and toolkit for high-resolution volumes // In ACM SIGGRAPH, Courses (p. 19). ACM, 2013; 
Schäfer, H., Niessner, M., Keinert, B., Stamminger, M., \& Loop, C. State of the Art Report on Realtime Rendering with Hardware Tessellation // InEurographics 2014-State of the Art Reports (pp. 93-117). The Eurographics Association, 2014.

Watt, M., Coumans, E., ElKoura, G., Henderson, R., Kraemer, M., Lait, J., \& Reinders, J. Multithreading for Visual Effects // CRC Press. - 2014. 